\title{
Correction to: Autologous Haematopoietic Stem Cell Transplantation in Multiple Sclerosis: a Review of Current Literature and Future Directions for Transplant Haematologists and Oncologists
}

\author{
Joyutpal Das ${ }^{1}$ - Basil Sharrack ${ }^{2}$ John A. Snowden ${ }^{3,4}$
}

Published online: 27 April 2019

(C) Springer Science+Business Media, LLC, part of Springer Nature 2019

Correction to: Current Hematologic Malignancy Reports https://doi.org/10.1007/s11899-019-00505-z

- In the 5th paragraph under the section "Efficacy", the phrase "...reported that NEDA was achieved..." should read as "...reported that cumulative NEDA was achieved..."

- In the 5th paragraph under the section "Efficacy", the phrase "...other data suggested that NEDA..." should read as "...other data suggested that yearly NEDA..."

- In Table 3, the phrase "...likely to significantly higher..." should read as "...likely to be significantly higher..."
- This information should be added as an article note in the front matter: "Basil Sharrack is a Member of the Autoimmune Diseases Working Party (ADWP) of the European Society for Blood and Marrow Transplantation (EBMT); John A. Snowden is a Chair of the Autoimmune Diseases Working Party (ADWP) of the European Society for Blood and Marrow Transplantation (EBMT)."

The original article has been corrected.

Publisher's Note Springer Nature remains neutral with regard to jurisdictional claims in published maps and institutional affiliations.

The online version of the original article can be found at https://doi.org/ 10.1007/s11899-019-00505-Z

Joyutpal Das

j.das@doctors.org.uk

Basil Sharrack

basil.sharrack@sth.nhs.uk

John A. Snowden

john.snowden@sth.nhs.uk

1 Sheffield Institute for Translational Neuroscience, University of Sheffield, 385a Glossop Rd, Sheffield S10 2HQ, UK

2 Clinical Neurology, Academic Department of Neuroscience, Sheffield Teaching Hospitals NHS Foundation Trust, Sheffield, UK

3 Blood and Marrow Transplantation, Department of Haematology, Sheffield Teaching Hospitals NHS Foundation Trust, Sheffield, UK

4 Haemato-oncology and Stem Cell Transplantation, Department of Oncology and Metabolism, University of Sheffield, Sheffield, UK 